\title{
The effect of nest aggregation on the reproductive behaviour of the peacock blenny Salaria pavo
}

\author{
J. L. Saraiva*†, E. N. Barataţ, A. V. M. Canárioł and \\ R. F. Oliveira* \\ *Unidade de Investigação em Eco-Etologia, Instituto Superior de Psicologia Aplicada. \\ Rua Jardim do Tabaco 34, 1149-041 Lisboa, Portugal, \$CCMAR-CIMAR Laboratório \\ Associado, Universidade do Algarve, Campus de Gambelas, 8005-139 Faro, Portugal and \\ $\S$ Departamento de Biologia, Universidade de Évora, Largo dos Colegiais 2, 7004-516 \\ Évora, Portugal
}

(Received 18 March 2008, Accepted 3 November 2008)

\begin{abstract}
The effect of nest aggregation in courtship behaviour was tested experimentally in an ecologically constrained, sex-role reversed population of the peacock blenny Salaria pavo. Mixed sex groups of eight males and eight females were tested in experimental tanks, containing eight potential nests either aggregated or dispersed. In the aggregated treatment, males spent more time inside their nests and monopolized other potential nests, causing a female-biased operational sex ratio (OSR). In the aggregated treatment, females also expressed more courtship behaviour. The results in general support the prediction that the aggregation of nests promotes male monopolization of potential nests, resulting in fewer nest-holding males and therefore a female-biased OSR that leads to the reversal of sex roles.

C) 2009 The Authors

Journal compilation $\odot 2009$ The Fisheries Society of the British Isles
\end{abstract}

Key words: operational sex ratio; resource monopolization Ria Formosa; sex roles.

\section{INTRODUCTION}

Emlen \& Oring (1977) provided an ecological framework for the evolution and expression of polygamous mating systems. In this seminal paper, it was proposed that the differences in the intensity and direction of sexual selection found in different species, and frequently between populations within the same species, are a consequence of the ability of a portion of the population to control the access of others to potential mates. This can be achieved either directly through the physical exclusion of competitors or indirectly through the monopolization of critical resources for reproduction.

In general, males have a higher potential reproductive rate than females, resulting in a male-biased operational sex ratio [OSR, i.e. the ratio of ready-to-mate males to ready-to-mate females (Emlen \& Oring, 1977; Kvarnemo \& Ahnesjö,

†Author to whom correspondence should be addressed. Tel.: +351 21881 17 00; fax: +351 2188609 541; email: jsaraiva@ispa.pt 
1996)]. Under these circumstances, males are the courting sex, there is high level of male competition to access mates, and females are choosy for potential mates. Sexual selection operating both through intra-sexual competition for breeding opportunities and through male mating preferences, however, is common in females (Clutton-Brock, 2007). For example, in some cases, male parental care may result in a lower potential reproductive rate in males than in females (Ahnesjö et al., 2001). This may result in the reversal of sex roles, i.e. females compete for access to mates and are the courting sex (Almada et al., 1995). Furthermore, sex-role reversal can occur within a population throughout the breeding season. In the two-spotted goby Gobiusculus flavescens (Fabricius), sex-role reversal occurs while the OSR becomes increasingly female biased towards the end of the breeding season due to a decrease in available nest-holder males in the population (Forsgren et al., 2004). Also, in the blenniid Petroscirtes breviceps (Valenciennes), a nest brooder with exclusive paternal care, sex-role reversal was found only in the middle of the breeding season when the availability of nesting sites is lower, therefore making the OSR female biased for a period of time (Shibata \& Kohda, 2006). These studies point to a special importance of resources (such as nesting sites) to the definition of a mating system. For example, the spatial aggregation of resources may limit the number of individuals who can actually breed, by exclusion of less able competitors (Emlen \& Oring, 1977; Hastings, 1988; Oliveira et al., 1999; Ahnesjö et al., 2001; Clutton-Brock, 2007). In fishes, this might be particularly relevant for cavity spawners with paternal care, in which both the ratio of sexually mature males and females and the availability of spawning sites may affect the OSR. In fact, the spatial aggregation of nest sites may lead to monopolization by a small number of males. This impedes the remaining males from accessing a nest and alters the number of individuals qualified to mate (Ahnesjö et al., 2001). In the common goby Pomatochistus microps (Krøyer), an experimental decrease in nest availability leads to a female-biased OSR and a shift in the sex roles, with females actively courting and competing for partners (Borg et al., 2002).

In the present study, the effect of nest aggregation on the reproductive behaviour of Salaria pavo (Risso) was tested. This species presents a promiscuous mating system in which both sexes have active courtship displays. This particularity allowed testing the effects of resource spatial distribution not only on males' territoriality and resource monopolization but also on the courtship of both sexes.

Salaria pavo inhabits the rocky shore of the Mediterranean Sea and adjacent Atlantic Ocean coast (Zander, 1986). In general, males are the courting sex and actively attract females into a hole or crevice in the rock that is used as a nest. In a territory around the nest, males display courtship that includes bright colouration, body jerking, figure-eight swimming and trying to chase females into the nest; females are typically more passive than males in their behaviour, sometimes responding to male initiatives by turning on a conspicuous nuptial colouration that consists on a pattern of brown and white bars, and by displaying fast opercular movements, and body jerks (Patzner et al., 1986). In Ria Formosa (Algarve, southern Portugal), a costal lagoon where adequate nesting substratum is scarce and highly aggregated, however, the sex roles are reversed 
and females lead the courtship (Almada et al., 1994, 1995). In this population, males nest in artificial reefs built by clam culturists in the muddy intertidal flats to delimit clam culture fields. These reefs are made of materials like bricks, tiles, stones and other debris. Brick holes are often used as nests and eventually adjacent holes are occupied by nest holders, so territories can be virtually absent. Since there is a high scarceness of nesting sites, many sexually mature males are unable to establish nests throughout the breeding season, and this seems to promote high levels of male competition for access to nesting sites (Almada et al., 1994). These ecological constraints seem to be responsible for a female-biased OSR since the low number of nest-holder males seems to limit the female reproductive potential as nests become filled with eggs (Almada et al., 1995; Oliveira et al., 1999). These factors seem to explain the sex-role reversal in this population of $S$. pavo, in which females are the courting sex and compete for access to mates. In the current study, the effect of nesting site aggregation on the reproductive behaviour of male and female $S$. pavo was tested experimentally. More specifically, it is predicted that the aggregation of nest sites will promote the monopolization of nests by males, resulting in a lower number of breeding males. Therefore, the OSR will become female biased with a concomitant increase in female courtship and intra-sexual aggression, paralleled by an increase in male intra-sexual and inter-sexual aggression and choosiness when nests are aggregated.

\section{MATERIALS AND METHODS}

The experiment was carried out in outdoor flow-through tanks $(1.2 \times 1.0 \times 0.6 \mathrm{~m})$ at the Ramalhete Experimental Station (University of Algarve) in the Ria Formosa, Portugal $\left(36^{\circ} 59^{\prime} \mathrm{N} ; 7^{\circ} 51^{\prime} \mathrm{W}\right)$. Sea water was delivered to the tanks from the station reservoirs and the outflow into the drainage pools. Two tanks, containing sand on the bottom and abundant sheltering provided by stones and shells, were used to maintain separately male and female stocks; two other tanks of similar size were used for the experiment. An eight-hole brick $(250 \times 195 \times 100 \mathrm{~mm})$ was placed in the centre of one of the tanks providing eight aggregated nesting sites (nearest nest distance $=5 \mathrm{~mm}$ ), hereafter designated aggregated treatment (AT). In the other tank, eight brick-made individual nesting sites $(250 \times 45 \times 45 \mathrm{~mm})$ were uniformly distributed (nearest nest distance $=20 \mathrm{~cm}$ ) along the wall of the tank and with the entrances facing the centre of the tank. This treatment is hereafter called dispersed treatment (DT) (Fig. 1). All potential nests had a $35 \times 35 \mathrm{~mm}$ entrance. The end of each brick hole was sealed with

(a)

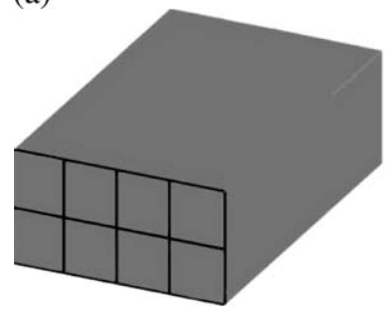

(b)

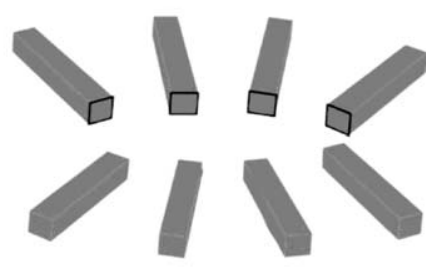

FIG. 1. Disposition of nest in the (a) aggregated treatment and (b) dispersed treatment. Not to scale. Distance between nest entrances in the dispersed treatment $=200 \mathrm{~mm}$. 
cement. A removable glass drawer was inserted inside each cavity so that the identity of the occupant of each nest and the number of eggs in the nest could be easily determined. These drawers were hermetic and had their entrance partially obstructed since both males and females prefer narrow entrances (Oliveira et al., 1999; Ruchon et al., 1999). Between replicates, the sand on the bottom was renewed and treatments were switched between the two tanks to avoid tank effects. New glass drawers were used in each replicate. Replicates were carried out with eight sexually mature fish of each sex.

Salaria pavo were captured during the breeding season in Ria Formosa and the experiment was carried out from May to July 2001 and in the same period in 2002. The fish were kept for at least 1 week in the stock tanks and were fed with sliced mussel Mytilus edulis while in the stock tanks and during the experiment. On the day before the experiment, males and females were anaesthetized with 1:12 000 MS-222 (ethyl 3-aminobenzoate; Sigma-Aldrich; www.sigmaaldrich.com), had their standard length $\left(L_{\mathrm{S}}\right)$ measured and were tagged with two coloured beads $(c .3 \mathrm{~mm})$ attached with a thread to the dorsal body muscle, immediately before the first ray of the dorsal fin (Patzner et al., 1986). Fish were left to recover in small aquaria with abundant aeration. The tags were very conspicuous both by direct observation and on video, allowing discrimination of individuals in a tank. Males and females were placed simultaneously in the experimental tanks $24 \mathrm{~h}$ prior to the start of the behavioural observations. Each replicate lasted for 4 days. Seven replicates were conducted for each treatment, three in 2001 and four in 2002 . The mean \pm s.E. $L_{S}$ and head crest size of fish between treatments did not differ (Wilcoxon $W$ unpaired test for $L_{\mathrm{S}}$ of males: AT $=98 \cdot 1 \pm 9 \cdot 5$ and DT $=$ $99.0 \pm 2.0 \mathrm{~mm}, n=7, P>0 \cdot 05$; Wilcoxon $W$ unpaired test for head height of males including crest: AT $=25.9 \pm 2.7$ and DT $=26.2 \pm 6.3 \mathrm{~mm}, n=7, P>0.05$; Wilcoxon $W$ unpaired test for $L_{\mathrm{S}}$ of females: AT $=69 \cdot 0 \pm 2 \cdot 0$ and DT $=69 \cdot 4 \pm 2 \cdot 5 \mathrm{~mm}, n=7$, $P>0.05$ ). Only females presenting an evident abdominal swell (an indicator of ripeness) were used. The mean \pm s.E. proportion of females in each treatment that released eggs upon abdominal pressure did not differ $(\mathrm{AT}=0 \cdot 16 \pm 0 \cdot 05$ and $\mathrm{DT}=0 \cdot 17 \pm 0 \cdot 05$, Wilcoxon $W$ unpaired test, $n=7, P>0 \cdot 05$ ). All the fish were released in good condition in the same place as their capture.

This study was carried out in conformity with ASAB guidelines and the Portuguese law on animal experimentation (1005/92, Project 'Hormones and Life History TradeOffs and Plasticity').

Video recordings were carried out twice a day at 0730 and 1730 hours, during the 4 days of the experiment. These sampling times are within the periods of higher spawning activity (Patzner et al., 1986). To control for order effects, the recording sessions started in a different treatment and in a different nest each day.

In the DT, the video image was centred at the nest entrance, covering an area of c. $30 \mathrm{~cm}^{2}$. Each focal sampling lasted for $10 \mathrm{~min}$, and the first $5 \mathrm{~min}$ were discarded as habituation time to the observer and camera. At the end of each focal sampling the camera was moved to the next nest and so on, providing a total of $40 \mathrm{~min}$ of observation per session. In the AT, the focal field covering the front of the brick and adjacent $30 \mathrm{~cm}^{2}$ of tank bottom was recorded continuously for $40 \mathrm{~min}$. As analysing nests individually in this treatment was virtually impossible due to the high proximity of the entrances $(5 \mathrm{~mm})$, the whole period of $40 \mathrm{~min}$ was analysed for all nests. This resulted in an asymmetry of nest focal time between treatments and so each fish individual focal time was estimated as the actual time that specific individual was visible in the film.

The behaviour selected for analyses were: female courtship, female intra-sexual aggression, male intra-sexual and inter-sexual aggression, time spent inside the nest and male courtship (Patzner et al., 1986). The focal observations were registered with The Observer ${ }^{\circledR}$ v.3 (Noldus; www.noldus.com).

Nest occupation was recorded twice a day after the video recordings took place. Removing the glass drawer and identifying the occupant assessed the occupation of the nests. The number of eggs was calculated by visual estimation of the area covered by the egg clutch (a priori observations revealed $c .80$ eggs per $\mathrm{cm}^{2}$ ). 
Variables that did not follow the parametric assumptions were analysed by nonparametric statistical methods. All tests were two-tailed and $\alpha=0 \cdot 05$.

Behaviour was expressed as frequency per time of observation (i.e. time during which the fish was visible in the video). Data are presented as means per replicate except when stated otherwise. The statistical analysis was performed using the freeware statistical analysis software ' $\mathrm{R}$ ' ( $\mathrm{R}$ Development Core Team, http://r-development_corp_team. software.informer.com/). In this software, the two-sample non-parametric test corresponding to Mann-Whitney $U$-test in other software packages is the Wilcoxon $W$ unpaired test (R Development Core Team).

\section{RESULTS}

A higher percentage of females courted the males (mean \pm S.E.: AT $=53.6 \pm$ 23.3 and DT $=5.3 \pm 6.0 \%$, Wilcoxon $W$ unpaired test $n=7, P<0.01)$ and with higher frequency (Fig. 2) in the AT. No significant difference was found in female intra-sexual aggression corrected for the exploratory behaviour (agonistic interactions between females per female nest approaches) (Fig. 3). Females visited more nests in the DT than in the AT (mean \pm s.E. AT $=0 \cdot 391 \pm 0 \cdot 131$ and $\mathrm{DT}=2 \cdot 059 \pm 0 \cdot 820$, Wilcoxon $W$ unpaired test $n=7, P<0 \cdot 01$ ).

Male intra-sexual or inter-sexual aggression did not differ between treatments (Fig. 3). Males spent a significantly larger proportion of time inside a nest in the AT than in DT [Fig. 4(a)], and the variability (s.E.) among males in the proportion of time spent inside a nest was also higher in AT (AT $=8.2 \pm$ $1 \cdot 7 \%$ and DT $=1 \cdot 1 \pm 0.4 \%$, Wilcoxon $W$ unpaired test $n=7, P<0.05)$. The maximum proportion of time inside the nest was higher in AT than in DT (mean \pm s.E. AT $=72 \cdot 0 \pm 12 \cdot 7 \%$ and DT $=12 \cdot 3 \pm 1 \cdot 4 \%$, Wilcoxon $W$ unpaired test $n=7, P<0.01)$ but no significant differences were found in the minimum time between the two treatments $(\mathrm{AT}=9 \cdot 2 \pm 7 \cdot 7 \%$ and $\mathrm{DT}=$ $4 \cdot 1 \pm 2 \cdot 7 \%$, Wilcoxon $W$ unpaired test $n=7, P>0 \cdot 05)$. Also, a higher proportion of nesting sites was occupied by males in DT than in AT [Fig. 4(b)].

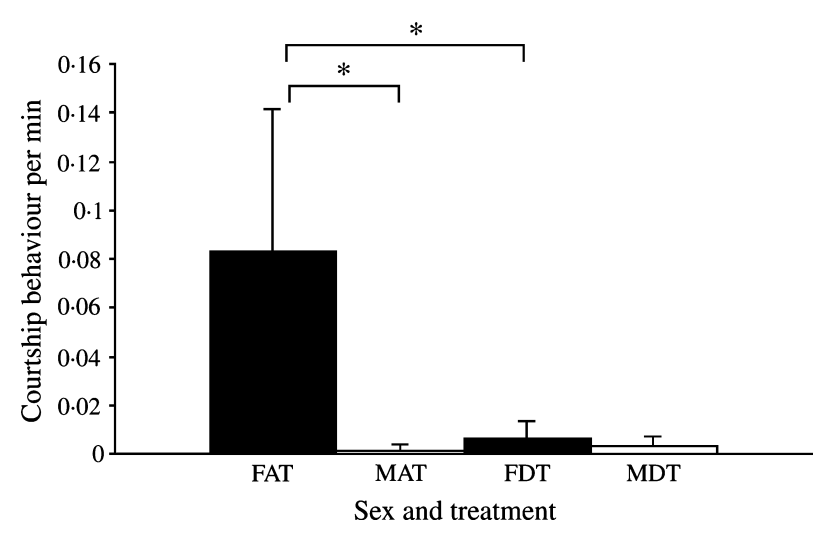

FIG. 2. Mean \pm s.E. courtship behaviour per minute of males and females in both treatments. FAT, females in the aggregated treatment (AT); MAT, males in the AT; FDT, females in the disappeared treatment (DT); MDT, males in the DT (female courting: Wilcoxon $W$ unpaired test $n=7, P<0 \cdot 05$; male courting: Wilcoxon $W$ unpaired test $n=7, P>0 \cdot 05$. FAT $v$. MAT courting: Wilcoxon $V$ paired test, $n=7, P<0 \cdot 05$. FDT $v$. MDT courting: Wilcoxon $V$ paired test, $n=7, P>0 \cdot 05)$. ${ }^{*}$, significant differences at $P<0 \cdot 05$. 


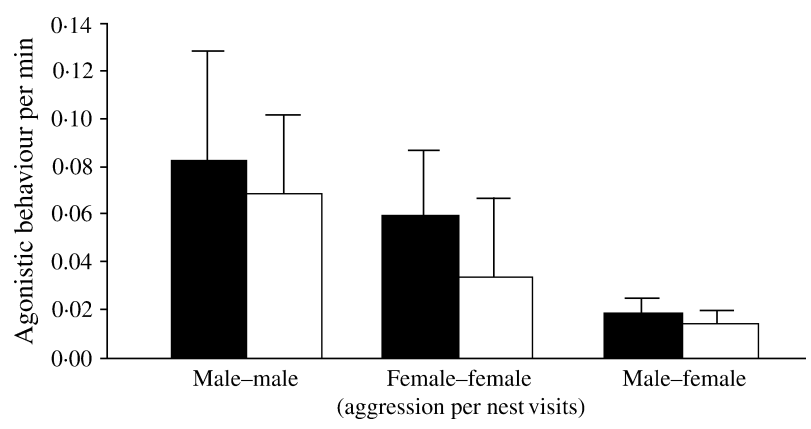

FIG. 3. Mean \pm S.E. agonistic interactions between individuals in aggregated $(\square)$ and dispersed ( $\square$ ) treatments (male-male: Wilcoxon $W$ unpaired test, $n=7, P>0 \cdot 05$; female-female: Wilcoxon $W$ unpaired test, $n=7, P>0.05$; male-female: Wilcoxon $W$ unpaired test, $n=7, P>0 \cdot 05$ ). NS, nonsignificant; *, significant differences at $P<0.05$.

No significant differences were found between treatments for the frequency of male courtship (Fig. 2) and proportion of courting males (mean \pm s.E. $\mathrm{AT}=3 \cdot 6 \pm 5 \cdot 8 \%$ and DT $=7 \cdot 1 \pm 4 \cdot 1 \%$, Wilcoxon $W$ unpaired test $n=7$, $P>0.05$ ). Females in the AT, however, courted significantly more than males, whereas the courtship frequency did not differ between sexes in DT (Fig. 2).

No significant difference was found in the proportion of males with eggs (mean \pm S.E. AT: $17 \cdot 9 \pm 12 \cdot 4 \%$ and DT: $19 \cdot 6 \pm 10 \cdot 7 \%$, Wilcoxon $W$ unpaired test $n=7, P>0.05$ ) or in the number of eggs between treatments (AT: 20.2 \pm 12.9 and DT: $15.9 \pm 9 \cdot 6$, Wilcoxon $W$ unpaired test $n=7, P>0.05$ ).

\section{DISCUSSION}

Nest aggregation seems to have promoted resource monopolization by some of the males, with a consequential female-biased OSR that resulted in higher frequencies of female courtship and female intra-sexual competition. The results indicate that fewer males in the AT were able to occupy nesting sites than in DT and that the few nest holders in the AT spent more time inside the nest than the higher number of nest holders in DT. This suggests an effort to monopolize several nests as valuable resources in the AT, which become economically defendable because of their spatial aggregation. In fact, the aggregation of nests altered the number of males qualified to mate, excluding those who did not gain access to a nest (Ahnesjö et al., 2001). Grant (1993) reports a parallel situation in food competition in several fish species and other vertebrates, where the spatial aggregation of food patches also promotes resource monopolization.

Since females spawn multiple clutches and males can receive clutches from several females, it could be argued that the female-biased OSR due to nest aggregation would not be as high as expected from theory. Nevertheless, a response in female behaviour to the treatments was detected. In fact, the low percentage of occupied nests in the AT resulted in about one nest-holder male to two mature females. In this female-biased OSR, females responded by courting more in the AT than in the DT, where the OSR was more even. This paradox can be explained by two non-exclusive mechanisms: (1) although there is enough nest 

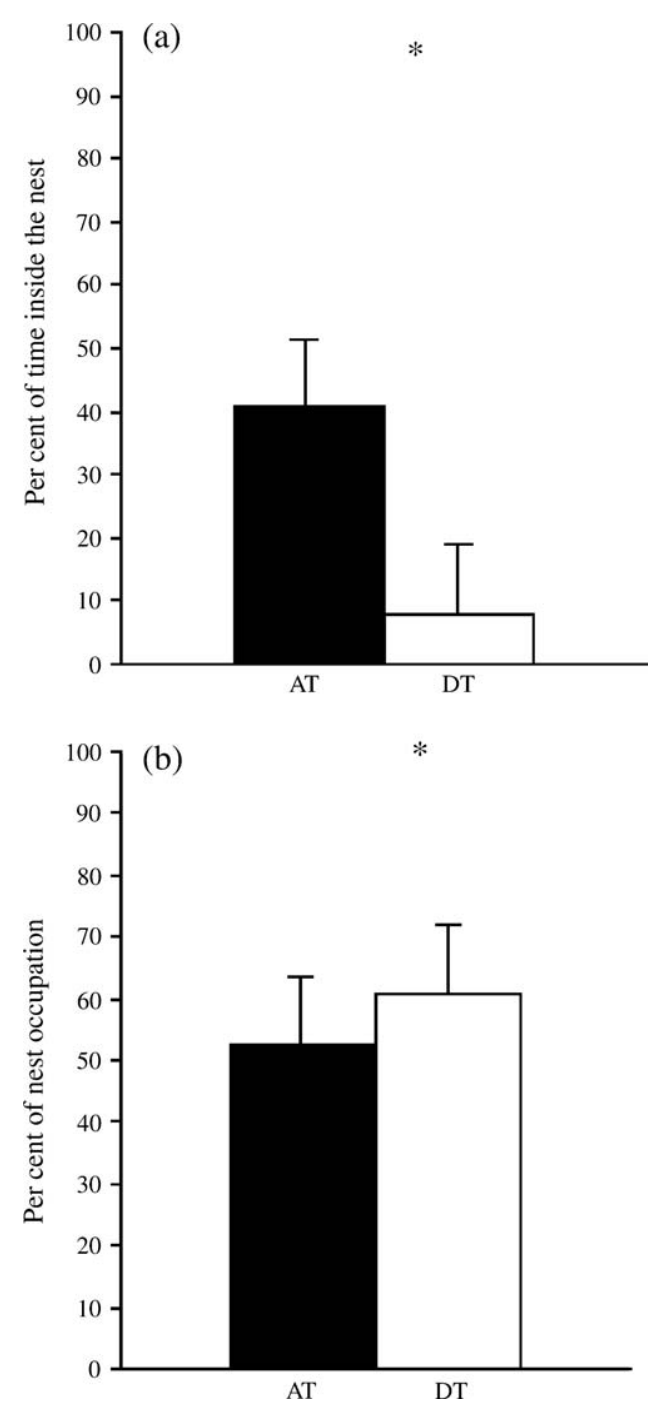

Fig. 4. Mean \pm S.E. (a) Proportion of time spent inside the nest by males (Wilcoxon $W$ unpaired test, $n=7$, $P<0.01$ ) and (b) Proportion of nest occupation (Wilcoxon $W$ unpaired test, $n=7, P<0.05$ ) in aggregated $(\square)$ and dispersed $(\square)$ treatments; *, significant difference at $P<0.05$.

surface to receive clutches from different females, they would have to take turns to spawn; apparently, S. pavo females do not adopt this queuing behaviour and the resulting overlap in spawning attempts by different females promotes female competition near the nest sites and (2) although on average there is only one more breeding male in the DT than in the AT, females in the AT have to aggregate in front of a single brick. This may lead to a perceived higher density by the females resulting in an increased rate of courtship.

Similar results were found by Forsgren et al. (2004) in the gobiid G. flavescens and emphasize the importance of factors that directly affect the OSR, especially in cavity spawners which seem to be heavily influenced by the availability of 
nesting sites (Almada et al., 1995; Oliveira et al., 1999; Ahnesjö et al., 2001). Also Shibata \& Kohda (2006) found dynamic sex roles in the blenniid P. breviceps, where the number of available nests showed only a small but significant fluctuation across the breeding season. Furthermore, the spatial aggregation of resources may also lead to increasing female intra-sexual competition for breeding opportunities in other animal groups, such as mammals (CluttonBrock et al., 2006).

Despite the fact that variability among males in the time spent in the nests was higher in the AT, the aggregation of nests did not result in higher male intra-sexual aggression. The explanation can lie in the fact that an increase in population density might be accompanied by mechanisms to avoid aggression and males might be using other mechanism of male-male competition. In the population of Ria Formosa, breeding aggregations of $S$. pavo are so dense that territories are virtually absent due to the high risk of nest takeovers (Almada et al., 1994). Nest-holder males restrain from leaving their nests and most behavioural activities, including courting females or feeding are restricted to the nest itself (Gonçalves \& Almada, 1998). It has also been observed that aggression among males does not seem to rise with increasing density of nest-holding males (Oliveira et al., 2001). As expected, in the AT males spent a larger proportion of time inside the nests suggesting that endurance instead of overt aggression is being used in male-male competition in this species. Furthermore, Borg et al. (2002) did not find differences regarding male-male competition in $P$. microps in a study where nest availability was manipulated, suggesting that sexual selection is still acting in males even when the OSR is female biased and females lead the courtship.

Males did not present differences in courtship between treatments. This result is supported by a field study that compared two populations of S. pavo living under different nest-site availability conditions that also found higher differences in female rather than in male behaviour (J. L. Saraiva, R. F. Oliveira, G. Pignolo \& J. Robalo, unpubl. data). A decrease in nest availability should increase the sexual selection pressure on females and elicit a higher response in direct competition. In males, the effect should be noted mainly on competition for access to nests rather than courtship, because although males were spatially separated in the DT, they were all in visual contact. This perception of competitors may constrain their courtship behaviour due to the risk of nest takeover (Almada et al., 1995). In populations of $S$. pavo living in rocky shores with no limitation of nest sites, the nests are hardly ever in visual contact (Patzner et al., 1986; J. L. Saraiva, R. F. Oliveira, G. Pignolo \& J. Robalo, unpubl. data). This would also help to explain why males also did not present differences in aggression between treatments since the perception of competition would still be present in the DT (although to a lesser degree).

Differences in male aggression towards females were expected to occur only when and if nest space available for spawning would become a limiting factor so that no more females can spawn. In fact, since there was no difference found in number of eggs or number of males with eggs, and these values were overall low, there was no apparent reason for males to reject females.

In conclusion, this study shows that aggregation of nests may bias the OSR towards females and decreases the number of males qualified to mate, thereby 
creating a competitive mating situation for females. This apparently leads to predominant female courtship and intra-sexual competition. The results found in this work suggest that nest aggregation has a clear effect on the dynamics of sex roles.

The authors would like to thank R. Serrano, L. Gomes, J. Nuno, S. Santos and M. Fernandes for help in various stages of the work, Ria Formosa Nature Park for the support and two anonymous reviewers for valuable comments. This study was funded by a Fundação para a Ciência e Tecnologia grant (PNAT/BIA/15090/99).

\section{References}

Ahnesjö, I., Kvarnemo, C. \& Merilaita, S. (2001). Using potential reproductive rates to predict mating competition among individuals qualified to mate. Behavioral Ecology 12, 397-401.

Almada, V. C., Gonçalves, E. J., Santos, A. J. \& Baptista, C. (1994). Breeding ecology and nest aggregation in a population of Salaria pavo (Pisces: Blenniidae) in an area where nest sites are very scarce. Journal of Fish Biology 45, 819-830.

Almada, V. C., Gonçalves, E. J., Oliveira, R. F. \& Santos, A. J. (1995). Courting females: ecological constraints affect sex roles in a natural population of the blenniid fish Salaria pavo. Animal Behaviour 49, 1125-1127.

Borg, A. A., Forsgren, E. \& Magnhagen, C. (2002). Plastic sex-roles in the common goby the effect of nest availability. OIKOS 98, 105-115.

Clutton-Brock, T. (2007). Sexual selection in males and females. Science 318, 1882-1885.

Clutton-Brock, T. H., Hodge, S. J., Spong, G., Russell, A. F., Jordan, N. R., Bennett, N. C., Sharpe, L. L. \& Manser, M. B. (2006). Intrasexual competition and sexual selection in cooperative mammals. Nature 444, 1065-1068.

Emlen, S. T. \& Oring, L. W. (1977). Ecology, sexual selection, and the evolution of mating systems. Science 197, 215-223.

Forsgren, E., Amundsen, T., Borg, A. A. \& Bjelvenmark, J. (2004). Unusually dynamic sex roles in a fish. Nature 429, 551-554.

Gonçalves, E. J. \& Almada, V. C. (1998). A comparative study of territoriality in intertidal and subtidal blennioids (Teleostei, Blennioidei). Environmental Biology of Fishes 51, 257-264.

Grant, J. W. A. (1993). Whether or not to defend? The influence of resource distribution. In Behavioural Ecology of Fishes (Huntingford, F. \& Torricelli, P., eds), pp. 137154. Chur: Harwood Academic Press.

Hastings, P. A. (1988). Female choice and male reproductive success in the angel blenny, Coralliozetus angelica (Teleostei: Chanopsidae). Animal Behaviour 36, 115-124.

Kvarnemo, C. \& Ahnesjö, I. (1996). The dynamics of operational sex ratios and competition for mates. TREE 11, 404-408.

Oliveira, R. F., Almada, V. C., Forsgren, E. \& Gonçalves, E. J. (1999). Temporal variation in male traits, nesting aggregations and mating success in the peacock blenny. Journal of Fish Biology 54, 499-512.

Oliveira, R. F., Almada, V. C., Gonçalves, E. J., Forsgren, E. \& Canario, A. V. M. (2001). Androgen levels and social interactions in breeding males of the peacock blenny. Journal of Fish Biology 58, 897-908.

Patzner, R. A., Seiwald, M., Adlgasser, M. \& Kaurin, G. (1986). The reproduction of Blennius pavo (Teleostei, Blenniidae) V. Reproductive behavior in natural environment. Zoologischer Anzeiger 216, 338-350.

Ruchon, F., Laugier, T. \& Quignard, J. P. (1999). A field experiment to test nest choice in the peacock blenny, Liphophrys pavo (Teleostei, Blenniidae). Vie et Milieu 49, 145-154.

Shibata, J. \& Kohda, M. (2006). Seasonal sex role changes in the blenniid Petroscirtes breviceps, a nest brooder with paternal care. Journal of Fish Biology 12, 203-214.

Zander, C. D. (1986). Blenniidae. In Fishes of the North-eastern Atlantic and the Mediterranean (Whitehead, P. J. P., Bauchot, M. L., Hureau, J. C., Nielsen, J. \& Tortonese, E., eds), pp. 1096-1112. Paris: UNESCO. 